\title{
Rancang Bangun Perangkat Lunak Agievic Berbasis Challenge And Respond Untuk Pengamanan Komunikasi Peer To Peer Video Conference
}

\author{
Agung Nugraha
}

\begin{abstract}
Kebutwhan untwk Layanan vided cowferencing menunjukkan poningkatan yang signifkan dalan bidang bisnis, militur dan penterintahan. Akan tetapi, sciring dengan borkembangmua pengganoan video conference, tentinny terdapat ancaman terhadap aplikasi video canforence sepent adara peryadapan dari pihak yang tidak berkepentingan. Proses otentikad pada sistem video conference juga dapat meniadi patensi ancaman dari pihak luar, yaühs dengan menalin pesan stream yang dikirim artara client dan server kemudian mengirim kembali pesan tersebut ke server whtuk mendapathan akses terhadap sistem.
\end{abstract}

Dalam makalah ini, dikembangkan sebuah perangkor huak video conference dengan menerapkan hibrid cryptasystem yang diberi nama Agievic Agievic menerapkan otentikasi dan key establishment antara clien dan server manggunakan sistem challenge respond berbasis public koy cryptasystem, sementara komunikasi video conference diamankan dengan menerapkan teknik enkripsi tuntuk data video dan audio menggunakan algoritma AES 256 bit dengan mode CTR

Berdasarkan hosif pengujtan, data yang dipenoleht pada saat peryadapan kamunikasi video canference tidak dapat dikenall sebagai data video dan awdio sehingga peryadar tidak dopat mengetahui komunikasi video canference yang sedang berlangsung. Adopun waktu rata-rata prases enkripsi don dekripsi pada komunikasi videa konferensi yaitu $6 l 49,1 \mathrm{f}$ mis.

Keywords - canference, otentikasi, hybrid, cryptosystem, Agievic

\section{PENDAHULUAN}

Video conference merupakan suatu Layanan komunikasi yang memiliki banyak keunggulan. Layanan ini dapat memungkinkan dua orang atau lebih melakukan komunikasi tatap muka secara real time di seluruh dunia melalui jaringan yang bersifat public maupun privale. Selain itu, video conference yang mendukung jaringan IP mempunyai kelebihan dalam hal performance, manajemen, pemakaian biaya, dan pengembangan untuk perusahaan yang bergerak dalam bidang komunikasi video conference [13]

Kebutuhan akan layanan video conference akhir akhir ini menunjukan peningkatan yang cukup signifikan. Hal ini dilihat dari berbagai survey yang telah dilakukan terhadap penggunaan aplikasi video conference. Seperti halnya survey yang telah dilakukan oleh Research Now dan Globul IP Solution. Dari survey tersebut dikatakan bahwa dari 1200 profesional di bidang bisnis dari negara Chins, Jepang, Amerika dan Korea Selatan telah menggunakan aplikasi video conference untuk keperluan bisnis dan pribadi [21]. Selain di bidang bisnis, peningkatan juga terjadi di bidang militer dan pemerintahan [13]. Sebagai contoh dalam bidang militer, teknologi video confenence memudahkan pimpinan di markas pusat untuk memberikan perintah atau strategi pada tentara yang sedang bertugas di lapangan [22]. Dalam pemerintahan, teknologi video conference digunakan oleh presiden untuk melaksanakan rapat dengan pemimpin negara lain.

Akan tetapi, teknologi video conference tersebut memiliki ancaman terhadap keamanan saat komunikasi berlangsung, Seseorang dapat melakukan penyadapan terhadap komunikasi video conference dan bisa dengan mudah merekam pembicaraan yang sedang berlangsung. Proses otentikasi sistem video conference juga dapat menjadi potensi ancaman dari pihak laar. Proses otentikasi dapat diserang dengan menyalin pesan stream yang dikirimkan diantara dua pihak dan mengirim kembali pesan tersebut kepada salah satu pibak untuk mendapatkan akses kepada suatu sistem. Oleh karena itu, diperlukannya pengamanan pada aplikasi wideo conference dengan tujuan untuk mengamankan komunikasi yang sedang berlangsung.

Apliknsi vidoo conference yang aman merupakan aplikasi yang didalamnya terdapat kombinasi dari teknik enkripsi dan otentikasi. Teknik enkripsi dapat digunakan untuk mengarmankan informasi yang akan dikirimkan, seperti user id dan password serta data video atau audio. Teknik otentikasi juga memungkinkan pihak yang mengirim informasi dapat memastikan bahwa informasinya terkirim pada pihak yang sah.

Dari permasalahan yang telah dijelaskan, maka akan dilakukan perancangan dan pembangunan perangkat lunak Agievic yang dapat digunakan untuk mengamunkan komunikasi sideo couference. Pernah 
dilakukan sebelumnya oleh peneliti lain yg relevan dengan penelitian yang dilakukan.

\section{LANDASAN TEORI}

\subsection{Kriptografi}

Kriptografi secara umum merupakan ilmu dan seni untuk menjaga kerahasian berita [10] Kriptografi juga dapat diartikan sebagai ilmu yang menpelajari teknikteknik matematika yang berhubungan dengan aspek keamanan informasi seperti kerahasiaan data, keabsahan data, integritas data, serta autentikasi data [5].

Ada empat tujuan meadasar dori kriptografi yang juga merupakan aspek keamanan informasi, yaitu sebagai berikut :

a. Kerahasiaan, adalah layanan yang ditujukan untuk menjaga isi informasi dari siapapun, kecuali pihak yang memiliki kunci rahasia untuk membuka informasi yang telah disandikan.

b. Integritas data, berhubungan dengan penjagaan dari perubahan data secara tidak sah. Untuk dapat menjaga integritas data, suatu sistem harus memiliki kemampuan untuk mendeteksi manipulasi data yang dilakukan pihak-pihak yang tidak berhak, antara lain penyisipan, penghapusan, dan pendistribusian data lain ke dalam data yang asli.

c. Otentikasi, berhubungan dengan identifikasi, baik secara kesatuan sistem maupun informasi itu sendiri. Dun pihak yang saling berkomunikasi harus saling memperkenalkan diri. Informasi yang dikirimkan harus diotentikasi keasliannya, isi datanya, waktu pengiriman, dan lain sebagainya.

d. Non-repudiasi, merupakan usaha untuk mencegah terjedinya penyangkalan terhadap pengiriman/terciptanya suatu informasi oleh yang mengirimkan/ membuat.

\subsection{Protokol Kriptografi}

Protokol merupakan prosedur untuk mencapai suatu maksud yang dilakukan oleh minimal dua pihak, dilaksanakan terurut duri awal hingga akhir yang tiap langkahnya harus dilakukan satu per satu dan berurutan [10].

Suatu protokol memiliki beberapa karakteristik lain yaitu:

1. Tiap pihak yang terlibat dalam protokol harus mengetahui protokol dan keseluruhan langkah yang akan dilaksanakan;

2. Tiap pihak yang terlibat dalam protokol harus setuju untuk mengikutinya;

3. Protokol hanus tidak ambigu, tiap langkah harus terdefinisi dengan jelas dan tidak ada peluang untuk ketidakpaltuman,
4. Protakol harus lengkap, harus ada tinda khusus untuk tiap kemungkinan situasi,

Protokol kriptografi adalah suatu protokol y menggunakan kriptografi. Protokol kriptog melibatkan penggunaan algoritma kriptografi dan tu protokol kriptografi lebih dari sekedar kerahasiaan [1

Tujuan utama penggunaan kriptografi dalam seb protokol adalah untuk mencegah atau pun mendet adanya penyadapan dan kecurangan yang dilakukan pihak yang terlibat dalam protokol maupun pihak luar protokol.

Terdapat tiga tipe protokol kriptografi, yaitu :

a. Arbitrated Protacol

Protokol ini menggunakan arbitrator da komunikasinya. Arbitrator adalah pihak ke terpercaya yang tidak berkepentingan melakukan tugas untuk menyelesaikan proto Protokol ini menjamin tidak terjadi kecurangan saat komunikasi terjadi antara ent: Tetapi, protokol ini mempunyai kekuran dalam sulitnya mencari pihak ketiga yang da jujur dan dapat dipercaya. Contoh dari prote yang menerapkan tipe Arbitrated Protocol adi Secure Electronic Transaction

b. Adjucticated Protocol

Adjudicator adalah pilhak ketiga yang d menilai suatu transaksi terlihat jujur atau t dalam suatu perselisihan. Artinya adalah pi ketiga yang dapat menilai apakah transaksi y sedang terjadi dapat dilakukan atau tic Protokol ini tidak mempunyai kemampuan da mencegah terjadinya kecurangan saat komunik Contoh dari protokol yang menerapkan Adudicated Protocol adalah Karberos Prolac

c. Self-enforcing Protacol

Protokol ini memberikan jaminan keadilan da berhubungan melalui protokol tanpa melibat pihak ketiga. Tetapi, protokol ini tidak de diimplementasikan pada setiap situasi kendisi. Contoh dari protokol yang menerap tipe Selfenforcing Protocol antara lain ad Diffie Hellman Key Exchange dan Authentica. Key Exchange Protokol 2.

\section{DESAIN}

Dalam perancangan aplikasi Ayievic, akan diguna protokol pada [6] yang terdiri dari proses otentikasi, establishment dan komunikasi. Dari tiga proses proto tersebut, diimplementasikan proses otentikasi dan establishment pada aplikasi Agievic sedangkan I proses komunikasi dilakukan modifikasi den mengimplementasikan protokol RTP yang diamar dengan algoritma AES 256 bit. 
Sistem Agievic terdiri dari dua entitas yaitu client dan server. Senver merupakan entitas yang berperan untuk menampung client yang ingin berkomunikasi. Ketika client ingin berkomunikasi dengan client lainnya, maka keduanya harus login terlebih dahulu ke server. Selain itu, server juga berperan sebagai Trasted-Thind Party (TTP) yang akan mendistribusikan random seed untuk menggenerate sexsion key pada setiap client. Client merupakan entitas yang melakukan komunikasi video conference secara aman dengan menggunakan aplikasi Agievic yang berkomunikasi secara point to poimt.

Aplikasi Agievic merupakan aplikasi yang dapat melakukan komunikasi video conference secara aman dengan mengimplementasikan teknik enkripsi dan ctentikasi. Aplikasi ini juga memiliki random generator yang digunakan untuk pembangkitan nilai random pada proses otentikasi dan pembangkitan session key untuk proses komunikasi antara client. Keamanan pada aplikasi Agievic yaitu terletak pada proses penyandian informasi baik pada proses otentikasi, pertukaran kunci maupun pada proses komunikasi antara client. Berikut ini merupakan gambaran dari sistem Ag̈levic.
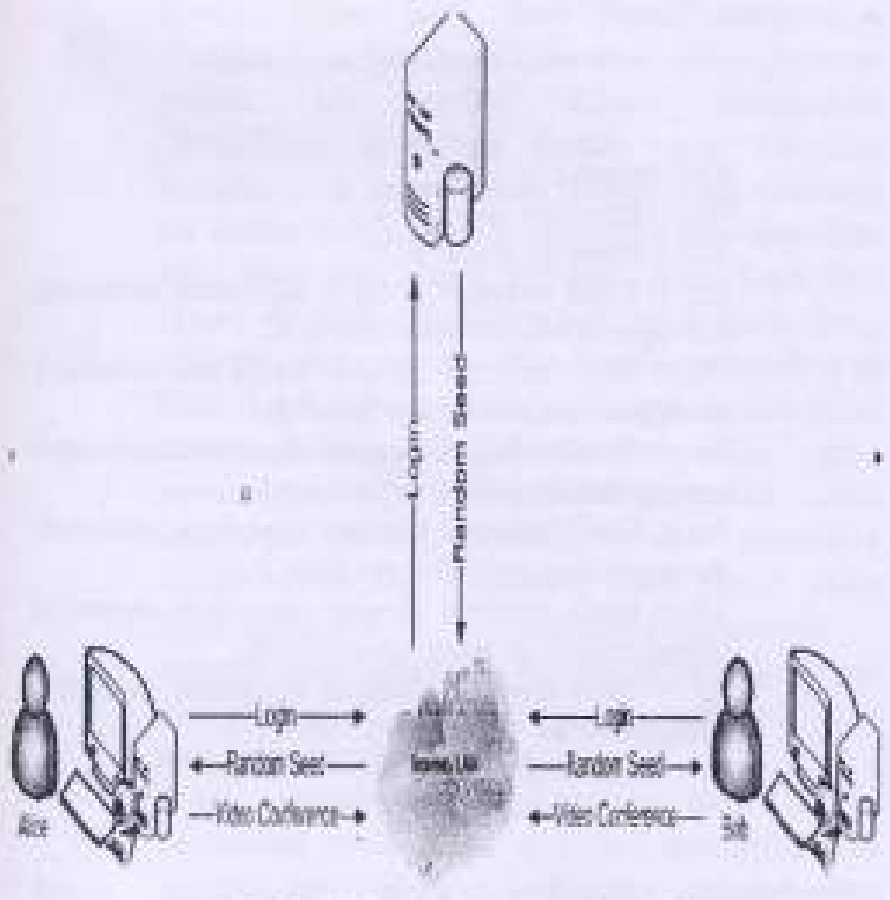

Garibar 1. Gambaran umamestiona Agievic

\subsection{Prases Otentikissi}

Proses otentikasi dilakukan oleh client dan server (murual authentication) dengan menggunakan sistem chaltenge respond. Tahap pertama pada proses ini yaitu diawali dengan client yang mengirimkan request kepada server untuk dapat masuk ke dalam sistem, Kemudian server akan memberikan respon dari request client. Server akan membandingkan data yang dikirim oleh cilent dengan data yang terdapat pada database server. jikat sesuai miaka chient dapat masuk kedalam sistorn
Gambar di bawah ini merupakan proses otentikasi pada aplikasi Agievic.

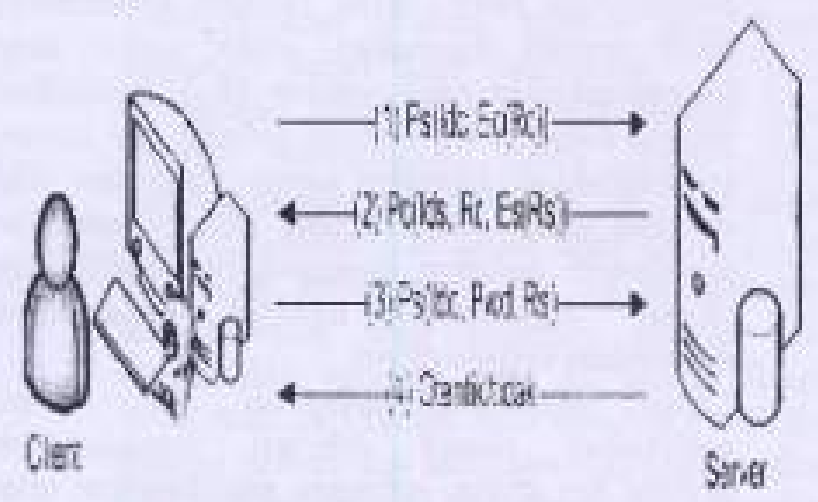

Ganbar 2, fruses Onentikasi

Keterangan :

$E_{c}=$ Hasil enkripsi dengan menggunakan private key milik cliem

Es = Hasil enkripsi dengan menggunakan private key milik server

Idc $=$ Identitas client

Ids $=$ Identitas server

$\mathrm{Pc} \quad=$ Hasil enkripsi dengan algoritma asimetrik menggunakan public key client

Ps - Hasil enkripsi dengan algoritma asimetrik menggunakan public key server $\mathrm{Rc}$ - Bilangan acak yang dibangkithan oleh client

Rs - Bilangan acak yang dibangkitkan oleh server

pwd $=$ Password

Penjelasan protokol proses otentikasi adalah sebagai berikut :

1) Client mengirimkan request kepada server untuk dapat masuk ke dalam sistem Agievic dengan cara membangkitkan nilai nandom ( $R c)$, nilai random $R c$ tersebat kemudian dienkripsi menggunakan private key client. Hasil enkripsi nilai random kemudian ditambahkan dengan identitas client (Ide) dan dienkripsi menggunakan public key server untuk kemudian dikirimkan kepada server.

2) Ciphertext yang diterima dari client didekripsi menggunakan private key server untuk mendapatkan Idc dan ciphertext Rc. Ciphertext Re tersebut didekripsi menggunakan public key client sehingga mendapatkan nilai random yang dikirimkan oleh client ( $\mathrm{Rc}$ ). Setelah itu server akan membandingkan $\mathrm{Re}$ dengan nilai random pada datahase, jika nilai Re tersebut sudah ada dalam dotabase, maka server tidak melanjutkan langkah protokol selanjutnya. Namun jika nilai Re iersefout tidak ada dalam dalabase, maka Re 
akan disimpan di darabase. Setelah dapat memastikan bahwa nilai random scbelumnya tidak pernah digunakan, maka server akan membangkitkan nilai random (Rs), melakukan proses enkripsi Rs dengan private key server. menambahkan identitas server (Ids) dan nilai random yang diterima dari client; kemudian melakukan enkripsi menggunakan public key client. Ciphertext tersebut selanjutnya dikirimkan kepada client.

3) Client menerima ciphertext dari server, melakukan proses dekripsi menggunakan privcue key client, sehingga mendapatkan nilai random yang dikirimkan oleh server (Rs) dengan mendekripsi menggunakan public key senver, mendapatkan identitas server serta mendapatkan nilai random yang sebelumnya dikirimkan kepada senver. Client akan membandingkan nilai random yant sebelumnya telah dibangkitkan dengan nilai yang diberikan olch server, jika nilai random tersebut berbeda, maka entitas yang dihubungi/berkomunikasi adalah semer yang tidak dikehendaki; sebaliknya jika nilai yang diterima adalah sama, maka client meyakini bahwa entitas yang dihubungiberkomunikasi adalah server yang berhak (terotentikasi). Jika client telah memastikan bahwa entitas yang dihubungi adalah server yang dikehendaki, maka client melakukan proses enkripsi identitas, password, dan nilai random yang telah diterima dengan menggunakan public key server. Ciphhertext tersebut kemudian dikirimkan kepada server.

4) Ciphertext yang diterima dari client didekripsi menggunakan private key server sehingga mendapatkan identitas dan password client serta nilai random yang sebelumnya dikírimkan kepada client. Jika nilai random yang diterima dari client sama dengan nilai yang dihangkitkan olch server, maka server meyakini bahwa entitas yang dihubungi/berkomunikasi adalah client yang berhak (terotentikasi). Jika server telah memastikan bahwa entitas yang dilubbungi adalah client yang dikehendaki, maka server akan membandingkan identitas dan password yang telah diterima dengan data yang tersimpan dalam dalabase server. Jika identitas dan password tersebut sesuai dengan darabase senver, maka client dapat tergabung dalam sistem. Sebaliknya, jika identitas dan password tidak sesuai dengan datahase server. maka client tersebut tidak dapat masuk dalam sistem.

\subsection{Key Establishnemt}

Proses key establishment hanya dapat terjadi sete client melakukan login kepada server. Saat cli melakukan request kepada senver untuk berkomuni dengan client lainnya dan chient yang dituju meneri request tersebut, maka server akan mengirim! rondom seed yang sama kepada kedua client y nantinya akan digunakan untuk pembangkitan sess key. Gambar di bawah ini merupakan proses establishment pada aplikasi Agievic.

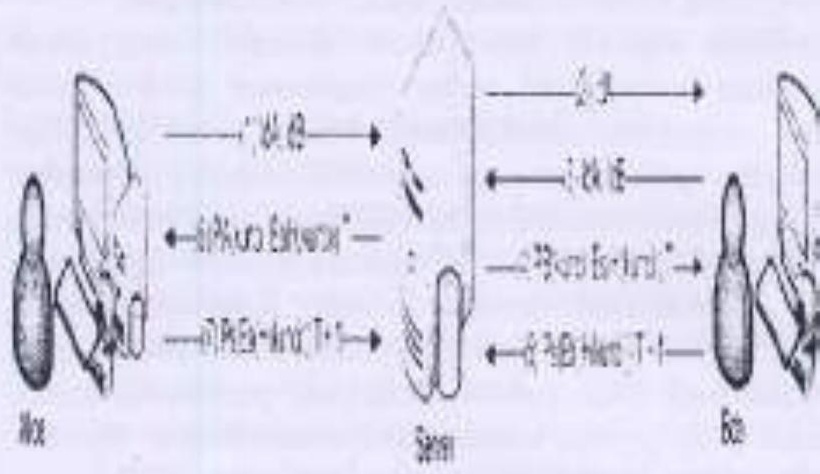

Gianbar 3. Proses Key Estabilshoment
Keterangan :
IdA $=$ I dentitas client A.
IdB = Identitas client B.
PA - Hasil enkripsi dengan algoritma asime menggunakan publickey dient $\mathrm{A}$.
PB - Hasil enkripsi dengan algoritmax asime menggunakan public key client $\mathrm{B}$.
Ps = Hasil enkripsi dengan algoritna asime menggunakan public key server.
$\mathrm{Ea}=$ Hasil enkripsi dengan algoritma asime menggunakan private key client A.
$\mathrm{Eb}=$ Hasil enkripsi dengan algoritma asime mengguakkan private ky client $\mathrm{B}$.
$E_{s}=$ Hasil enkripsi dengan algoritma asime menggunakan private key server.
$\mathrm{H}=$ fungsi hash.
$\mathrm{T}=$ timestamp.

Penjelasan protokol yang digunakan un penyediaan kunci Agjevic adalah sebagai berikut :

1) Client melakukan request komunikasi kep. server dengan mengirimkan identitas diri dan identitas client lain yang akan dihubung

2) Server menerima permintaan panggi komunikasi dan melihat status client penerit jika status client penerima tidak aktif, m: server akan mengirimkan pesan kepada $\mathrm{cl}$. pernanggil bahwa client yang dituju sed: tidak aktif. Namun jika status client peneri aktif. maka semer akan menenus permiataan tersebut dengan mengirim 
identitas client yang meminta panggilan komunikasi kepada client penerima.

3) Client menerima permintaan panggilan komunikasi dan mengirimkan identitas dirinya dan identitas elient lain yang menghubunginya.

4) Server menerima respond persetujuan, membangkitkan nilai random yang digunakan sebagai random seed untuk komunikasi cllent. Server membuat digital signature dari random seed tersebut dengan cara memasukan random seed ke dalam fungsi hash, hasil dari fungsi hash tersebut dienkripsi dengan private key miliknya dan digabungkan dengan random seed dan timestamp, kemudian dikirimkan kepada client penerima (client yang menerima panggilan komunikasi).

5) Client penerima menerima ciphertext yang dikirimkan oleh server, kemudian melakukan dekripsi dengan menggunakan private key miliknya, sehingga mendapatkan kunci dan timestamp serta ciphertext dari nilai hash kunci. Nilai hash dari kunci didapatkan dengan mendekripsi clphertext menggunakan public key server. Client melakukan identifikasi keutuban kunci yang diterima dengan cara memasukan kunci yang diterima ke dalam fungsi hash, sehingga mendapatkan nilai hash dari kunci tersebut. Nilai hash dari kunci dibandingkan dengan nilai hash yang dikirim oleh server. Jika hasil perbandingan nilai hash tersebut adalah sama, maka nilai kunci tidak mengalami kerusakan atau perubahan. Jika client telah yakin akan integritas kunci, maka client penerima membuat digital signature dari kunci yang telah diperoleh, menggabungkannya dengan timestamp +1 dan melakukan enkripsi menggunakan public key server lalu mengirimkannya kepada server.

6) Server menerima ciphertext dari client kemudian melakukan dekripsi menggunakan private key miliknya, sehingga mendapatkan digital signature kunci dan timestamp +1 yang dikirimkan client. Kemudian senver melakukan identifikasi mengenai keutuhan kunci yang dikirim sebelumnya dengan cara membandingkan digital signature kunci dan timestamp yang diterima dengan yang dikirim sebelumnya. Jika digitai signature kunci yang dikirimkan client tidak sestai dengan yang dikirim scbelumnya, maka protokol akan kembali pada langkah empat (4) atau jika timesoump yang diterima sutuh terdapat dalam datahase, berarti teridentifikasi langkah pada protokol ini sebagai replay attack, sehingga protokol akan terhenti. Namun jika digital signature kunci atau timestamp +1 yang dikirimkan client telah sesuai dengan yang dikirim sebelumnya, maka Serwer akan membangkitkan nilai random yang digunakan sebagai random seed untuk komunikasi client. Kemudian senver membuat digitol signature dari random seed tersebut, dengan cara memasukan random seed ke dalam fungsi hash, hasil dari fungsi hash tersebut dienkripsi dengan private key miliknya dan digabungkan dengan random seed dan timestamp, kemudian dikirimkan kepada cliemt pemanggil (client yang meninta panggilan komunikasi). Client pemangiil menerima ciphertext yang dikirimkan oleh server, kemudian melakukan dekripsi dengan menggunakan private key miliknya, schingga mendapatkan kunci dan timestamp serta ciphertext dari nilai hash kunci. Nilai hash dari kunci didapatkan dengan mendekripsi ciphertext menggunakan public key server. Client melakukan identifikasi keutuhan kunci yang diterima dengan cara memasukan kunci yang diterima ke dalam fungsi hash, sehingga mendapatkan nilai hash dari kunci tersebut. Kemudian nilai hash dari kunci yang diterima tersebut dibandingkan dengan nilai hash yang dikirim oleh server. Jika hasil perbandingan nilai hash tersebut adalah sama, maka nilai kunci tidak mengalami kerusakan atau perubahan. Jika client telah yakin akan integritas kunci, maka elient pemanggil membuat digital signature dari kunci yang telah diperoleh, kemudian menggabungkannya dengan timestamp +1 dan melakukan enkripsi menggunakan public key server dan mengirimkannya kepada server.

\subsection{Proses Komumikas!}

Komunikasi video conference dilakukan oleh client secara point to point tanpa melibatkan server. Untuk melakukan proses komunikasi secara aman, client akan menggunakan session key hasil dari pembangkitan randont generator dengan input random seed dari server. Session key tersebut digunakan sebagai input kunci pada penyandian dats video dan undio menggunakan algoritma $\mathrm{AES}$.

Komunikasi video conference pada aplikasi Agiovic menggunakan protokol RTP. Oleh karena itu, akan digunakan suatu proses yang dapat mengirimkan paket data video dan audio melalui protobol RTP. Selain itu, digunikas juga suatu moses yang darat melakukan 
enkripsi dan dekripsi terhadap data video dan andio yang dikirimkan. Gambar berikut ini merupakan proses komunikasi video conference pada aplikasi Agievic.

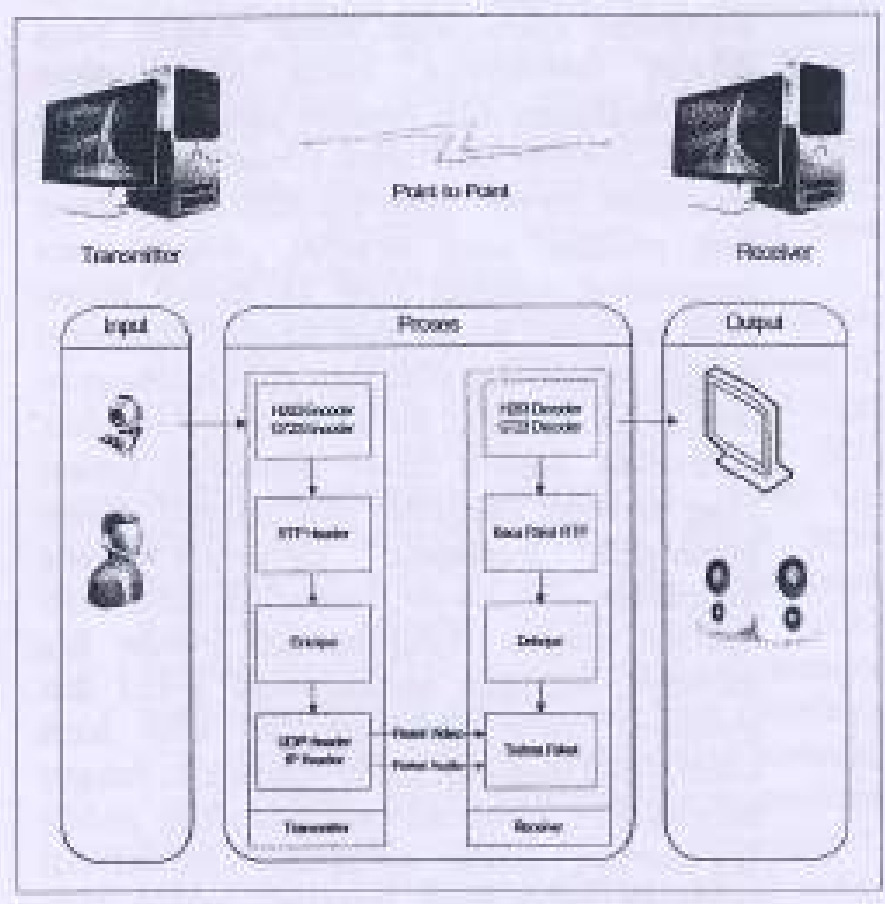

Gamber 4. Kornunikasi fideo congerence aplikasi Agievic

Pada komunikasi video conference, protokol RTP menggunakan dua buah port yang masing - masing digunakan untuk melakukan transmisi data video dan andio. Proses transmisi dimulai ketika aplikasi melakukan capture video dan audio dari device yang digunakan. Setelah melakukan capture, data video dan andio tersebut dikompresi menggunakan codec yang telah ditentukan yaitu $\mathrm{H} 263$ untuk video dan G723 untuk andio. Data yang telah dikompresi dibentuk menjadi paket RTP dengan diberikan header RTP dan dienkripsi menggunakan algoritma AES 256 dengan mode CTR. Ciphertext yang telah dihasilkan tersebut kemudian dibentuk menjadi paket UDP yang siap untuk ditransmisikan. Gambar berikut ini merupakan susunan paket data yang dienkripsi dan siap ditransmisikan.

\begin{tabular}{|c|c|c|}
\hline & \multirow{3}{*}{$\underset{\rightarrow}{\text { Enkripsi }}$} & IP Header \\
\hline RTP Header & & UDP Header \\
\hline Payload & & Ciphertext \\
\hline
\end{tabular}

Gembar 5. Susunan paket yang siap ditrasmisikan

Proses penerimaan paket data pada uplikasi Agievic dimulai ketika data diterima oleh aplikasi. Saat data diterima, dati kemudian didekripsi menggunakan algoritma dan kunci yang sesuai. Oleh karena itu, kunci yang digunakan untuk mendekripsi tidak ses maka paket data tidak dapat dikenali sebagai paket RTP sehingga aplikasi tidak dapat menjalankan vi dan andio yang dikirim. Jika kunci yang diguna sesuai maka data video dan oudio yang didapatkan a didecode menggunakan codec yang sesuai ur selanjutnya dijalankan olch aplikasi.

\section{IMPLEMENTASI DAN PENGUJIAN}

Implementasi aplikasi dilakukan pada OS berb Windows yang terkoneksi dengan jaringan intemet. user mengaktifkan aplikasi untuk pertama kali m akan muncul tampilan login. Pada tampilan \& terdapat field usemame dan password yang harus oleh user untuk dapat terkoneksi dengan server. Gan 4.1 meaumjukkan tampilan ketika user melakukan $I$ kepada server.

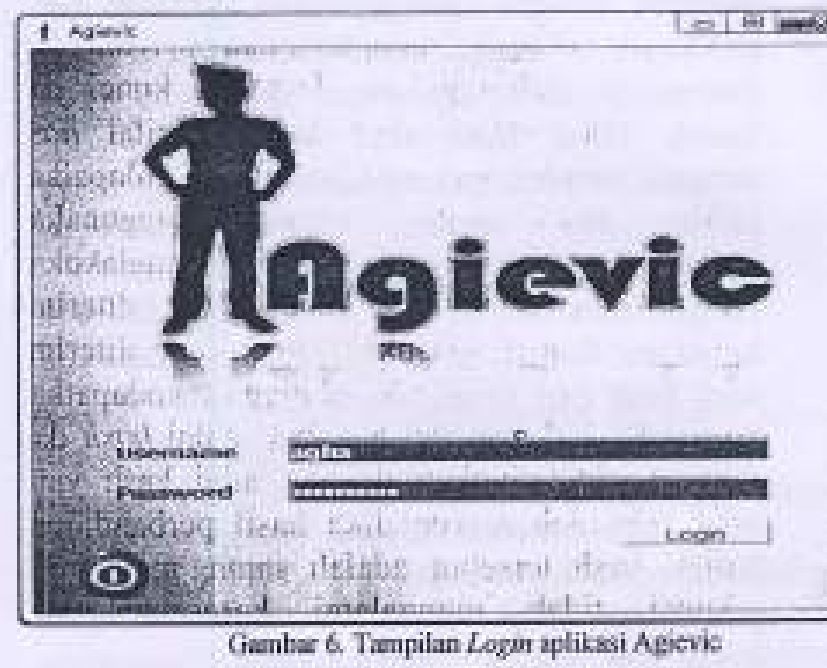

Pada proses koneksi ke server, terjadi pr, otentikasi antara client dan server yang dilakukan se mutual azthentication, sehingga jika kedua entitas di memastikan bahwa pihak yang dihubungi adalah ben pihak yang sah, maka client dapat masuk ke da sistem Agievic. Untuk melakukan komunikasi vi conference dengan user lain, maka user terlebih dat memilih user tojuan yang online pada list user on lalu menckan tombol call. Permintaan panggilan a disampaikan ke server dan server akan meneris panggilan kepada user tujuan. Jika user yang dipan sedang tidak melakukan komunikasi video conferc dan panggilan tersebut diterima, maka aplikasi so otomatis akan memberitahukan server bahwa pange diterima. Selanjutnya user dapat melakukan komuni video conference secara point to point tanpa melibat server. Gambar dibawah ini menunjukkan tamp utama aplikasi Agievic ketika user berhasil online terdapat user lain yang ingin berkomunikasi. 


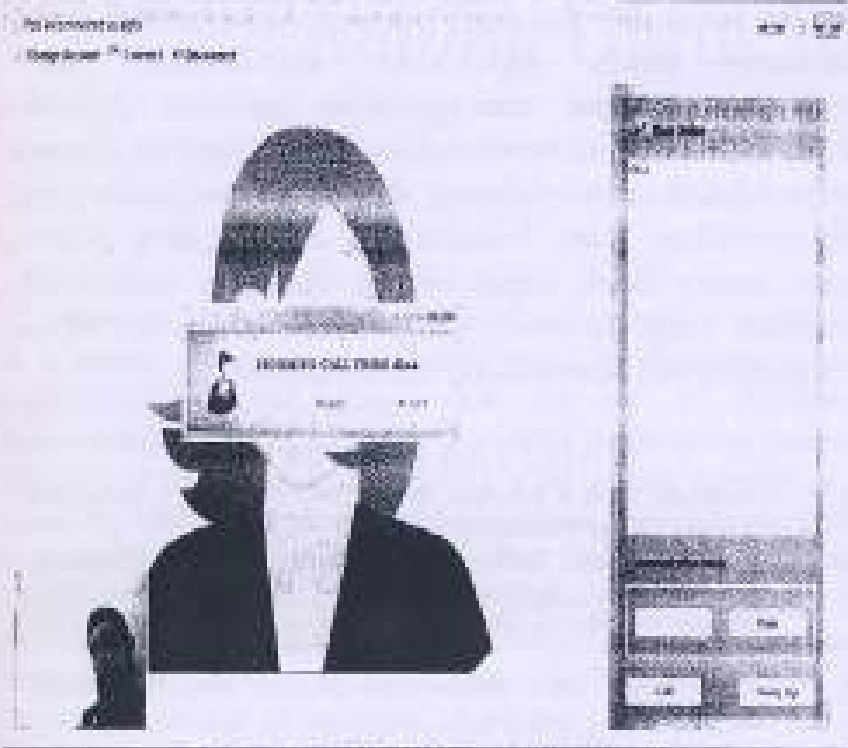

Gambar 7. Tampilan Ltama uplikasi Agievic-

Mode komunikasi pada aplikasi Agjevic terdiri dari 2 yaitu mode plain dan secure. Mode komunikasi ini ditujukan ketika komunikasi video conference sedang dilaksanakan. Ketika sesi komunikasi video conference dimulai antara 2 client, aplikasi menjalankan mode plain, user dapat mengganti mode tersebut dengan menekan tombol secure. Sebaliknya, user juga dapat mengubah mode secure menjadi plain dengan menekan tombol plain.

Server mempunyai layanan untuk menetima proses login dari client dan permintaan komunikasi video conference. Ketika server diaktifkan, maka secara otomatis server membuka koneksi TCP pada port 56565. Dengan menggunakan port tersebut, client mengirimkan permintaan ke server untuk melakukan proses login ataupun komunikasi video conference. Sttiap permintaan yang dilakukan oleh client akan ditampilkan pada aplikasi server. Aplikasi senver juga menampilkan client yang telah melakukan login kepada sistem. Gambar berikut ini menupakan tampilan pada aplikasi serwer ketika terdapat client yang melakukan permintaan kepada sener.

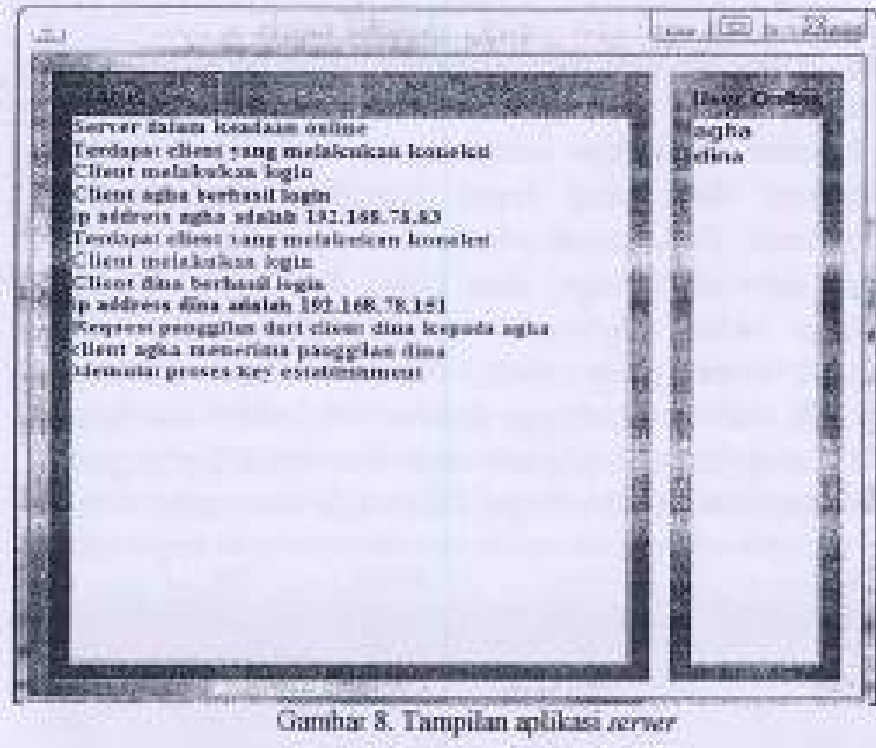

Pengujian dilakukan dengan melakukan perhitungan waktu yang dibutuhkan oleh aplikasi ketika melakukan komunikasi video conference dalam mode secure dan mode plain. Perhitungan waktu dimulai ketika aplikasi melakukan capture video dan audio yang akan ditransmisikan dari sisi pengirim sampai dengan paket data video dan audio dijalankan di sisi penerima. Pengujian dilakukan sebanyak 50 kali dan selanjutnya data yang didapatkan akan dibandingkan. Berikut ini merupakan grafik basil pengujian kecepatan aplikasi Agievic.

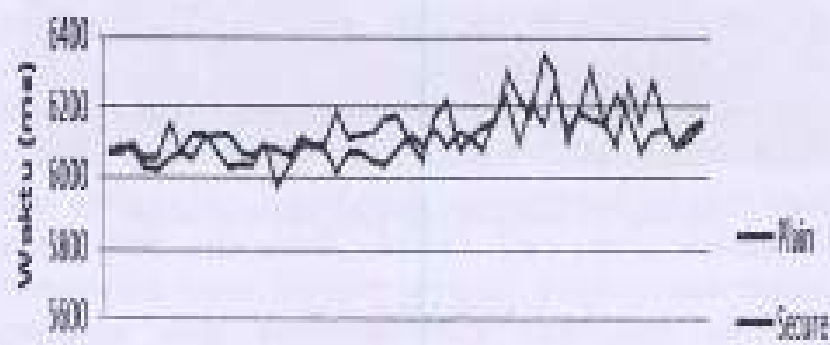

\section{9}

\section{Perebernt}

Cambar 9. Ginfilk perbandingan waltur mode ptam ifas secture

Berdasarkan data hasil pengujian (data terlampir), waktu rata - rata aplikasi melakukan komunikasi video conference pada mode plain dan secure masing masing adalah $6101,74 \mathrm{~ms}$ dan $6140,14 \mathrm{~ms}$. Sehingga selisih waktu rata - rata yang didapatkan adalah $38,4 \mathrm{~ms}$ Pengujian keamanan dilakukan dengan tujuan untuk mengetahui proses pengamanan video conference pada aplikasi Agievic. Pada pengujian ini akan dilakukan penyadapan terhadap komunikasi video conference dengan menggunakan sofoware Wireshark. Penyadipan terhadap transmisi video conference tersebut dilakukan 
baik ketika aplikasi menggumakan mode secure maupun mode plain.

Setelah dilakukan penyadapan, terdapat perbedaan mengenai data yang dapat ditangkap oleh sofweare Wireshark. Pada mode plain, data yang ditransmisikan dapat dikenali sebagai data video dan cusdio. Berbeda dengan video conference yang menggunakan mode secure, data yang akan ditransmisikan dienkripsi terlebih dahulu schingga ketika dilakukan capturing, data yang ditangkap pada saat transmisi berlangsung tidak dapat dikenali sebagai data video dan audio.

\begin{tabular}{|c|c|c|c|}
\hline Soese & Desination & Prosocal. & Wto \\
\hline 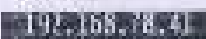 & 29280952653 & Brista & 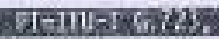 \\
\hline $1025168,78,52$ & $192 \times 69 \times 154$ & H. 263 . & $9 T-174-18.265$ \\
\hline 192.158 .2855 & 292.10078 .41 & $\mathrm{H} 263^{\circ}$ & F-TाU-T 11.263 , \\
\hline $192,163,18,34$ & 192.16978 .41 & H. 26332 & $8-\pi \mathrm{U}-7$ H.26: \\
\hline 1921168.78 .53 & $492.165 ., \times .41$ & H. 203 & 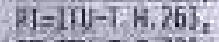 \\
\hline $192,16586,23$ & 192, 5519857 & Eing3. & $9 \mathrm{~T}-\mathrm{In}=\mathrm{I}, \mathrm{G}, 22 \mathrm{~S}_{\mathrm{S}}$ \\
\hline 192.158 .8 .5 & $792 \times 69,7 \mathrm{E}-11$ & HC263: & R-I U-T. \\
\hline 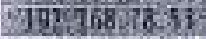 & 142.360986.45 & $1+26320$ & (2) \\
\hline 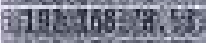 & 192255+2ast & inlings: & 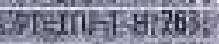 \\
\hline 19245621853 & 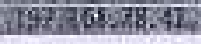 & & \\
\hline
\end{tabular}

Gientar, 10. Data video dan andio pods mode plain

\begin{tabular}{|c|c|c|c|}
\hline Soure & Detrution & Plowed & wo \\
\hline 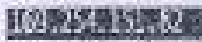 & 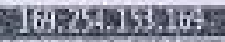 & ख्या: & 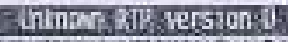 \\
\hline 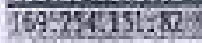 & 169.25:15.56? & 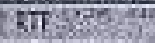 & 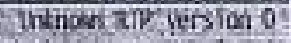 \\
\hline & M102:251103:159 & mikle & Whinow NIP sersionto \\
\hline & 180 & BIP & 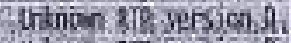 \\
\hline & & 8] & Whan RP? \\
\hline & 209 & RIP & thenow XPR \\
\hline f.15]:15s: & $169.25+15 \mathrm{~K}, \mathrm{~K}$ & RIR. & thioiva RIR versich 0 \\
\hline & 162 351:15I: 82 & RIS: & 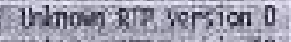 \\
\hline & 205:8x & REP & Whom are uecsicn:D \\
\hline 1531 & 6332828 & RIR & Irlnown kup yersion \\
\hline
\end{tabular}

Gamber. 1L. Data vidoo dan aadio pada moóo secume

\section{KESIMPULAN}

Aplikasi Agievic mengimplementasikan hybrid cryptosystem baik pada proses otentikasi, key establishment dan komunikasi sesuai dengan protocol pade (Prakasa, 2008). Protokol ini didesain untuk resisten terhadap replay attack dengan mengimplementasikan timestamp pada proses key establishment dan random number pada proses otentikasi. Otentikasi pada protokol ini menggunakan sistem challenge-respond dan proses otentikasi dilakukan oleh kedua belah pitak (client dan server). Pada proses key establishment, sener membangkitkan random seed yang akan digunakan oleh client untuk membangkitkan session key dalam komunikasi. Pada proses komunikasi, dilakukan modifikasi dengan mengimplementasikan protokol RTP yang ditambahkan proses enkripsi dan dekripsi data video dan audio.
Melalui langkah - langkah pengamanan tersebut $m$ sescorang dapat melakukan komunikasi vic canference dengan menggunakan aplikasi Agic secara aman. Hal ini berdasarkan hasil pengujian dim ketika dilakukan penyadapan, data video dan azdio y: ditransmisikan saat komunikasi berlangsung da mode secure tidak dapat dibaca sehingga menam kesulitan bagi pihak yang tidak berbak un mengetahui sesi komunikasi video conference.

\section{DAFTAR PUSTAKA}

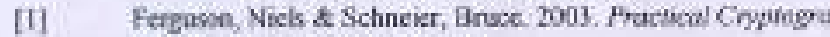
Indiasa : Wiley Pubtishing, tax.

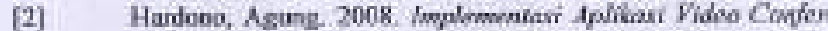
Mempounakon Algoribxu Blonefinh Birbanis fonz A Fremevork. Skripsi tidak diberbitkan. Banding Institut Tekn Telikom.

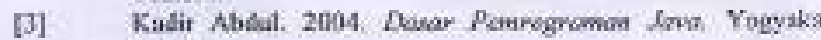
ANDI

[4] Meneres, Alfred 1. et.at. 1997. Handloosk of Apy Copsograghy. Newyork: CHC Press.

[5] Minir, Risaldi 2006. Kripozreyil. Bundung ; Infoentatike

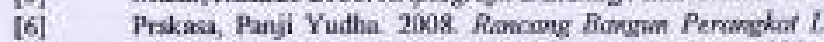

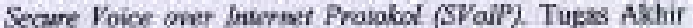
diterbikan. Begos, Sckolah Tinggi Sandi Negana.

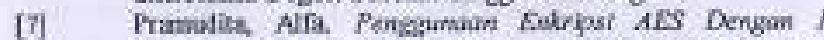

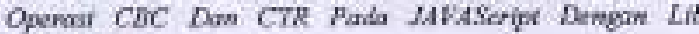
Pideryet

[8] Privangenro, Sigit. 2006. Membnat Medid Ploper dingun Media Frawerwark (JMED) 2, J. Jikarta : IlmuKomputer Com.

[9] Roseribers, Douz \& Stepbens, Most 2007. Usr Cave D Obucr Modeling vilh UMiL. Apress.

[10] Schneit, Bruse. 1996. Arolked Copragnumby, Second Ed Prorocols, Aleorfims and Seutes Cade in C. Newyork: Wibog a Suns, Ine.

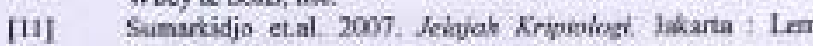
Sandi Negara RI.

[12] Terry, Andi Jifa 200n, Rancang Fangrn Daw Analiar Qus

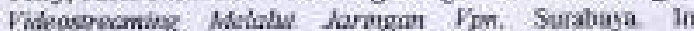
TeknobgiS stpaluh Noperiber.

(19) Weinskin In M. 2005. Emoriogng $I T$-lewel Securthy fo Vudeoconferencing. Wainbouse Reseirch.

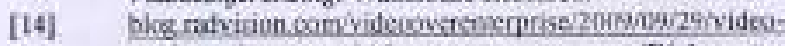

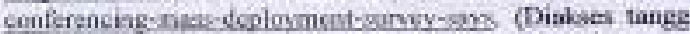
Mert 20tii)

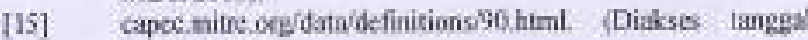
Marct 2010)

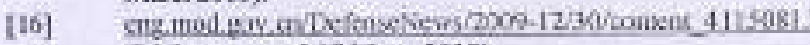
(Dinkses tanegal $17 \mathrm{Maret} 2010$ )

[17] Benprociconv Military htth (Dialses tanggal 17 Marct 2010).

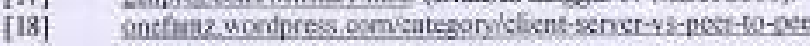
(Dxatses tangeal 31 Mare 2010 .

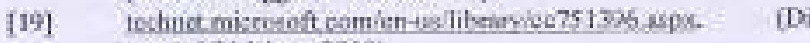
tirregal 21 Miret 20 :3)

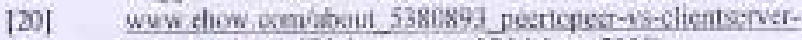
netusiss . aml (Diakses tanggal 21 Maret 2010).

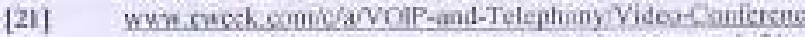
00 the Rise-Survey-Shows=137811? (Diskses tanged 21 N. 2010).

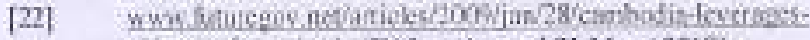

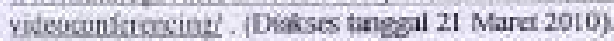

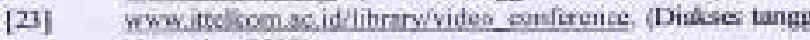
Nopenter 2000)

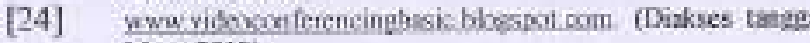
Muret 2010). 